\title{
VIRGÍLIO DE LEMOS: O INTELECTUAL EM TRÂNSITO
}

\author{
Luciana Brandão Leal \\ Pontifícia Universidade Católica de Minas Gerais
}

Resumo: Este artigo tem por objetivo investigar alguns traços significativos da poética de Virgílio de Lemos, que através da polifonia revelou-se rebelde e transgressora em relação ao modelo literário vigente em Moçambique. O poeta criou novas imagens e vocabulário, imprimiu novo ritmo a sua poesia, a fim de revelar os múltiplos saberes culturais presentes em seu país. A produção dos vários heterônimos (Duarte Galvão, Bruno Reis e Li Lee Yang) revela o esforço para acompanhar as inovações trazidas pelas vanguardas europeias, pelo modernismo brasileiro, além de romper com os paradigmas coloniais. Para o estudo aqui proposto, foram selecionados alguns textos publicados na antologia Eroticus Moçambicanus (1999), organizada por Carmen Lúcia Tindó Secco (UFRJ). Esse livro reúne os ciclos representativos da obra virgiliana, especialmente o que foi produzido entre 1944-1963. Da lírica virgiliana sobressaem a irreverência e a transgressão, constituindo-se como uma atitude subversiva em busca da identidade, além do grito de um poeta inconformado frente à repressão colonialista.

Palavras-chave: Identidade. Poesia. Polifonia. Resistência. Virgílio de Lemos.

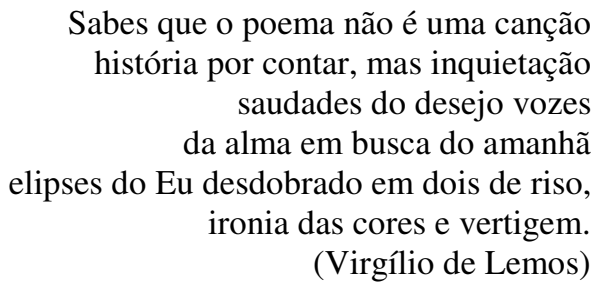

Nos cinco países que assumiram a língua portuguesa como idioma oficial, Angola, Cabo Verde, Guiné-Bissau, Moçambique e São Tomé e Príncipe, o intelectual africano encontrava-se, até a data da independência, imerso em duas realidades bem distintas: a sociedade colonial e a sociedade africana. A escrita literária representava, então, a tensão entre esses dois mundos: tensão advinda da utilização de uma língua europeia em um contexto divergente daquele encontrado no país colonizador. Souza e Silva (1996), no livro Do alheio ao próprio: a poesia em Moçambique, argumenta que o intelectual colonizado é um sujeito

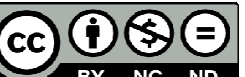

BY NG ND Esta obra está licenciada sob uma Licença Creative Commons.

\footnotetext{
* Mestre em Letras - Literaturas de Língua Portuguesa, pela Pontifícia Universidade Católica de Minas Gerais. Professora de Língua Portuguesa e suas literaturas.
} 
marcado pelo dilaceramento e pela fragmentação: em certa medida, é submetido a se inserir numa realidade brutalmente objetiva - sua terra dominada por estrangeiros; mas, por outro lado, persegue a expressão de sua identidade e da própria condição de colonizado.

Transitando por esses dois contextos, os intelectuais assumiram heranças advindas dos movimentos vigentes na Europa, além de marcas peculiares dos dialetos locais, características que emergem da produção literária oriunda dos países africanos citados. Maria Nazareth Soares Fonseca afirma que "nessa fase o escritor africano assume a responsabilidade de construtor, arauto e defensor da cultura africana" (FONSECA, 2007, p. 02). Na poética de Virgílio de Lemos encontramos a assimilação e, ao mesmo tempo, a reinvenção da língua portuguesa. O poeta promove um processo de "mestiçagem" entre a variedade ensinada nas escolas, tida como padrão, e as expressões faladas pela população moçambicana.

Virgílio de Lemos nasceu no tumultuado ano de 1929, na Ilha de Ibo, uma das que integra o arquipélago das Quirimbas, na costa norte de Moçambique. Antes de completar três meses de idade, transferiu-se para Lourenço Marques, hoje denominada Maputo. Diz Mia Couto: "Quem assim nasce, troca e destroca de margens, condenado à existência indecisa entre cais e viagem. Nossa alma ficou avizinhando esse mar que costura caminhos no oriente". (COUTO, 1999, p. 15). Em entrevista publicada na antologia Eroticus Moçambicanus (1999), Lemos afirma trazer em si, além da herança lusitana, traços longínquos do Oriente, cujo legado se mantém vivo na cartografia de Ibo e Moçambique: “Os barulhos do exterior/ invadem-me. Artificialmente/ preenchem o vazio". 1

Carmen Tindó Secco observa que "Virgílio de Lemos é outro poeta, cuja obsessão pelas ilhas do Índico é intensa" (SECCO, 2006, p. 20). A análise de sua obra deixa transparecer a adoração pelo mar, através de analogias e metáforas múltiplas, que se revelam em movimentos vertiginosos, lembranças e reminiscências advindas do inconsciente do poeta. $\mathrm{O}$ oceano remete ao retorno às origens, e oferece elementos para construções surreais, como o azul infinito da imaginação criadora. No posfácio escrito para o livro Eróticus Moçambicanus, Fernanda Angius argumenta:

Tornam-se recorrentes, no discurso poético de Virgílio, palavras como: cor, brilho, ouro, azul, imagem etc. Do retracto do outro que lhe foge ou se deixa aprisionar, passamos à descrição pictória de quadros em que as ondas e o erotismo vibram de tal modo, que os seus movimentos e modulações sonoros nos atingem os ouvidos, o olfacto e, sobretudo, o olhar. Jogo de sinestesias e de espelhos, a poesia de Virgílio de Lemos aparece-nos aqui como uma paleta de pintor onde estão concentradas todas as cores de que nasce o quadro em que se representa o homem movimentandose num cenário em que as pulsões socioculturais se esbatem para dar lugar a um

\footnotetext{
${ }^{1}$ GALVÃO, Duarte. Artificialmente, 1999, p. 22.
} 
sujeito lírico que interroga o mundo e nele se entrega à aventura de viver (...). (ANGIUS, 1999, p. 137-138)

Em seu Dicionário de Símbolos, Jean Chevalier justifica que "o azul é a mais profunda das cores: nele, o olhar mergulha sem encontrar qualquer obstáculo, perdendo-se até o infinito, como diante de uma perpétua fuga da cor". (CHEVALIER, 2009, p. 107). Em Miradouro $^{2}$, alusão a um ponto de onde é possível vislumbrar o horizonte, a voz poética sugere imagens e cores: "Retrato/ no bolso que resiste ao tempo/ do azul ao azul/ a ave/ traça o seu grito/ e diz/ o seu adeus/ ao mar". Os movimentos, os sons e as formas se fundem no azul, desaparecem, como um pássaro no céu. "Imaterial em si mesmo, o azul desmaterializa tudo aquilo que dele se impregna”. (CHEVALIER, 2009, p. 107). A cor que inspira o poeta, representa o caminho do infinito, onde o real se transfigura em imaginário. Como no poema transcrito abaixo, essa nuance desliza pelos versos, perdendo-se nas águas que inundam os olhos de pranto, de lembranças e saudades, evocações do paraíso perdido:
A tentação dos azues
Mar tão exoticamente azul que me esqueço do azul diáfano mar como um vulcão polvo cólera acalmada perversa erótica voz do mar azul que é fantasia mar d'estrelas de água e
fundos espelhos de raiva submarina e secreta flora e fauna sensual emoção na sedução azul do mar diálogo vibrações chorando ou rindo
vozes que fogem à reflexão e à razão e são apenas mar de combates solitários mergulhos do azul no azul despedaçados mastros naus de guerra
de estupro intoleráveis testes dos extremos frágeis corpos inenarráveis mortes meias verdades silêncios dramáticos azuis na intolerância dos ventos. ${ }^{3}$

Filho de portugueses "ultramarinos" que trabalhavam para Coroa, ainda muito cedo precisou compreender o que se passava entre dois universos tão diferentes: o da família abastada (tipicamente burguesa) e o dos nativos, servos da casa. "Este homem é crioulo não na língua, mas no coração”. (COUTO, 1999, p. 16). Desde pequeno, Virgílio de Lemos fora um leitor interessado, profundamente influenciado pela mãe, Ilda, e pelo tio, Cisco, quando se trata do amor pelas palavras. "A presença da mãe e do tio marcaram a inclinação do menino para a literatura e para as artes". (FONSECA, 2008, p. 44). A língua portuguesa era o idioma

\footnotetext{
${ }^{2}$ GALVÃO, Duarte. Miradouro, 1999, p. 87.

${ }^{3}$ LEMOS, Virgílio. A tentação dos azues, 1999, p. 67.

${ }^{4}$ Esta informação biográfica está disponível em MELO, Rosicler Ferraz de. O erotismo na poesia de Virgílio de Lemos (1944-1963): o eu que recorda. [Dissertação de Mestrado]. Faculdade de Letras da UFRJ, 2003.
} 
ensinado nas escolas, mas o poeta apreendeu palavras das línguas africanas locais, através de histórias contadas pelos nativos.

\begin{abstract}
Através da errância dessa poesia que objetiva desvendar as fendas e fraturas da própria identidade, as vozes poéticas retornam aos espaços matriciais da colonização, percebendo que até estes locais se encontram cindidos pelas lembranças de culturas várias, em que estavam presentes tanto as tradições e os ritmos africanos das etnias negras do chão banto, como as marcas ocidentais trazidas pelos portugueses e os temperos acres deixados pelos comerciantes árabes e pelos indianos. (SECCO, 2006, p. 21).
\end{abstract}

O poeta, cuja produção literária é vasta e se encontra, em grande parte, ainda inédita (em revistas e jornais para os quais o artista escreveu e antologias literárias publicadas na África e na Europa), propôs entre os anos de 50 e 60 um lirismo bastante particular: revelador das múltiplas interferências culturais presentes na constituição social moçambicana. As palavras do autor confirmam o desejo de colorir suas poesias com as mais variadas nuances, influências e vozes:

$\mathrm{Na}$ minha linguagem poética há muitas expressões ligadas ao nada; influência sartreana, claro, não é particular em mim: o tema já aparece em Shakespeare, Wordsworth, Pessoa - que também leu Shakespeare - Ezra Pound, e também em Reinaldo Ferreira, em Cecília Meireles... Chamo atenção para Cecília Meireles porque ela é uma poetisa que nós já líamos em Moçambique, e é muito ligada ao mar. Se lermos com atenção, veremos este recurso sempre ligado à imagem do nada: vamos do nada para o nada. Estilhaçamento da imagem e busca desta. (LEMOS, apud MELO, 2003, p. 28).

Virgílio de Lemos foi um dos precursores na luta pela criação de uma poiesis moçambicana, antropofágica e transgressora em relação aos parâmetros literários impostos pela colonização. Como nos lembra Mia Couto, "Moçambique, nessa altura, vivia sob domínio português. Antecipados estávamos à nação. Lutar pela identidade desse país foi um sonho". (COUTO, 1999, p. 15). No poema Antropofagia Delirante, assinado pelo heterônimo Duarte Galvão, os primeiros versos anunciam a relação entre o poeta e sua língua: "Mas qual o poeta que não tem/ incestuosa/ uma relação com a língua/ qual a língua que não devora/ o poeta?" "A língua é uma canção/ que assobias/ que devolves à memória/ sem artifícios nua/ irreverente outra/ e tua". ${ }^{6}$ Entretanto, a lírica virgiliana não se circunscreveu apenas às nuances locais, cumpriu revelar anseios universais. "E de tanto e/ tão pouco saber/ mágica magia/ na absorção/ da linguagem/ crioula e universal." ${ }^{7}$ Nessa concepção, a poesia de Virgílio de Lemos se afasta da busca de uma identidade hermética, presa a moldes pré-

\footnotetext{
${ }^{5}$ GALVÃO, Duarte. Antropofagia delirante, 1999, p. 32-33.

${ }^{6}$ GALVÃO, Duarte. Antropofagia delirante, 1999, p. 32-33.

${ }^{7}$ LEMOS, Virgílio. De profundis, 1999, p. 59.
} 
fixados; conclama, na verdade, a simbiose cultural, a diversidade, as trocas e imbricações, o que é aclarado na poesia Inefável luz do eterno:

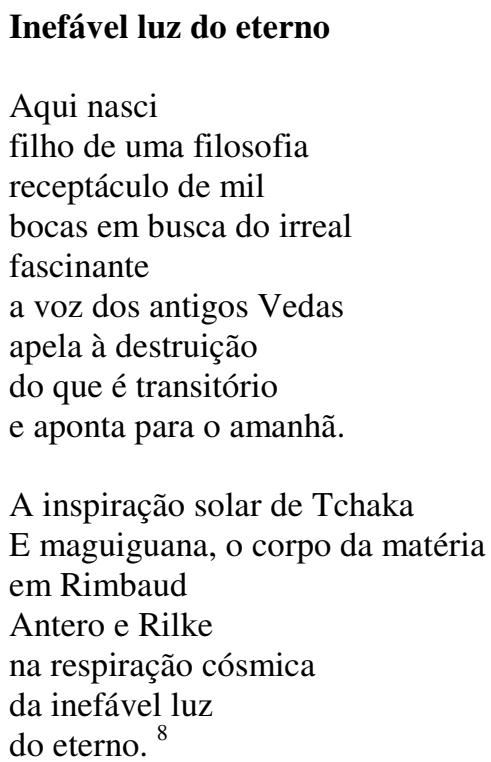

Nesse poema, o eu-lírico se apresenta consciente da dilacerada identidade de Moçambique, um país multifacetado, com heranças africanas, portuguesas, árabes e indianas. Mia Couto (1999) sugere que a própria nação moçambicana é ainda categoria ficcional, o que é evidenciado pelos versos: "Aqui nasci/ filho de uma filosofia/ receptáculo de mil/ bocas em busca do irreal/ fascinante.” Na perspectiva de Carmen Tindó Secco (2006), a riqueza poética de Virgílio de Lemos advém da incorporação do universal, elaborado através da sua singular forma de expressão. Sua lírica revela que a transição das formas negritudianas opera-se em um processo que pressupõe outras contribuições - das vanguardas européias, da literatura portuguesa e brasileira - inclusive as da própria negritude. "A inspiração solar de Tchaka/ E maguiguana, o corpo da matéria/ em Rimbaud/ Antero e Rilke”.

Percebe-se também a presença dos mitos, ressoa "a voz dos antigos Vedas", além da “inspiração solar de Tchaka/ E maguiguana”, uma intertextualidade com o saber simbólico de diferentes regiões de Moçambique. Os mitos trazem a representação da origem dos povos, sua memória, seus heróis e façanhas; dramatizando a vida social e a história. Para Platão, o mito consiste em uma maneira de traduzir aquilo que pertence à opinião, mas não pode ser cientificamente provado. Sejam quais forem os sistemas de interpretação, eles ajudam a perceber uma dimensão da realidade humana e trazem à tona a função simbolizadora da imaginação. Sem se comprometer com a verdade científica, o conhecimento mítico expressa a verdade de determinadas percepções. Para Alfredo Bosi, "a resposta ao ingrato presente é, na

${ }^{8}$ GALVÃO, Duarte. Inefável luz do eterno, 1999, p. 24. 
poesia mítica, a ressacralização da memória mais profunda da comunidade”. (BOSI, 1977, p. 153) O crítico literário acredita que a poesia trabalhará, através da intertextualidade com os mitos, a linguagem da infância recalcada, a metáfora do desejo, o texto do Inconsciente e dos sonhos. Em Pátria do meu canto, o eu-lírico faz clara menção à polifonia aqui tratada, quando nos primeiros versos anuncia: "Sussurram dentro de mim/ as almas dos mortos/ sonâmbulos deuses/ anónimas vozes".

\section{Pátria do meu canto}

Sussurram dentro de mim
as almas dos mortos
sonâmbulos deuses
anónimas vozes
a tradição no seio
do futuro
que nas trevas
crio.
No silêncio da bruma
memória
de mágoas e mitos
que erram
pelo tempo singular
fora do tempo
coração que devora
o amor
pátria do meu
canto
índico grito.

Ao explicar as razões que o levaram a denominar Orpheu o primeiro ciclo de sua poesia (1944-1951), Lemos afirma que sua visão de Orpheu, sob as perspectivas da criação de uma Arte que transitasse em diversos espaços, "representava uma abertura contra o isolacionismo" (LEMOS, 1999, p. 148). Essa mesma abordagem ele queria estender à sua criação literária, em uma tentativa de "abrir a poesia à poesia, à criatividade, às vivências do outro, dos outros, mundialmente" (LEMOS, 1999, p. 149). Através desse movimento de incorporação do outro, a poesia se libertaria dos nacionalismos e regionalismos estreitos, além de figurar como estratégia de resistência ao fascismo e outras formas de autoritarismo. Virgílio de Lemos afiança: "Eu sonhava ir mais longe com a poesia. Pretendia buscar experimentalismos poéticos, em suma, uma outra linguagem que fizesse a poesia imergir no fundo de si mesma, para daí, sair renovada" (LEMOS, 1999, p. 149). Na tentativa de emancipação da poética moçambicana, como produto estético autônomo e independente, o poeta se empenhou em promover intertextualidade com os movimentos das vanguardas

\footnotetext{
${ }^{9}$ LEMOS, Virgílio. Pátria do meu canto, 1999, p. 69.
} 
europeias e brasileiras, assim como o dadaísmo, o surrealismo e o Movimento Pau-Brasil, e, sobretudo, com diversas correntes da Negritude. O artista propunha, por conseguinte, "o mergulho abissal na própria poesia e uma antropofagia cultural, capaz de libertar a literatura moçambicana dos parâmetros coloniais que a cerceavam" (LEMOS, 1999, p. 149). No poema Insólito, um espanto espantado de sim mesmo, escrito em 1951, e dedicado a André Breton, Fernando Pessoa, João Cabral de Melo neto e à mãe, Ilda; o eu-poético, ávido por liberdade, faz bailar várias vozes e tendências artísticas surgidas nas primeiras décadas do século XX. Sua língua e seu discurso são enriquecidos pela intertextualidade com outros poetas, tanto clássicos quanto contemporâneos, brasileiros e europeus.

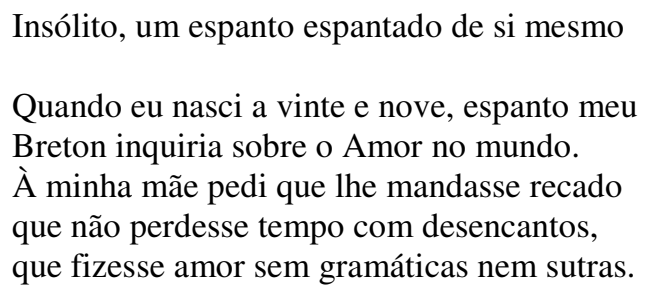

$[\ldots]$

Quando eu nasci em vinte e nove, grito de revolta a meio do mar, eu vela eu balão isoboiando saudei o mundo o dadaísmo Kafka Dostoiévski Tchekov Camões e Eça, Assis

[Graciliano e Pau-Brasil de Andrade.

Os velhos me falaram do Rio capital de Moçambique, pimenta ouro e escravatura início dos Oitocentos. Quando eu nasci surpresa rebentei a Bolsa a minha mãe olhos azuis e loura que tangava e sabia nadar e o craque fez valsar Chicago Londres Frankfurt e libra-ouro rainha fez rir meus tios José e Cisco fez tremer os cofres do tesouro. Ibo não mais foi capital. Salvo no meu coração.

\section{$[\ldots]$}

Quando eu nasci em vinte e nove temporalidade sem tempo sem antes nem depois kimwane-persa Salomé meio cega falava na Babilónia Constantinopla Sevilha, barrocos, sedas e talvez por isso guarde em mim este ar de espanto espantado de si mesmo, borgiano como se adivinhasse as coisas ávido de liberdade, corpo interior solto, sereno face à morte seio, exuberância, gozo em mim dos deslimites. ${ }^{10}$

Como já mencionado, Virgílio nasceu em 1929, marcado pelo signo do surrealismo de Breton e pela eclosão dos movimentos de vanguarda. Em Insólito, um espanto espantado de si mesmo, o poeta revisita os acontecimentos e personagens que marcaram a história mundial. Os versos do poema mencionam, por exemplo, o crack na Bolsa de Valores, em

${ }^{10}$ GALVÃO, Duarte. Insólito, um espanto espantado de si mesmo, 1999, p. 24-26. 
Nova Iorque: "Quando eu nasci surpresa rebentei a Bolsa", que fez "valsar Chicago Londres Frankfurt/ e libra-ouro rainha". Virgílio de Lemos, sob o pseudônimo de Duarte Galvão, adota a escrita automática, sem pausas, marcas que sugerem a subjetividade inconsciente, além de incorporar a velocidade de seu tempo.

$\mathrm{Na}$ criação virgiliana o sujeito poético demonstra sentir-se "um estrangeiro para si mesmo", partindo-se em vários "cacos" para expressar o estilhaçamento da imagem interior. Em um movimento aparentemente contrário, o eu-lírico procura sua identidade múltipla através do corpo da poesia. Mia Couto (1999) observa: dividido enquanto ser, a estratégia da escrita de Virgílio de Lemos não poderia ser outra senão a dispersão, os heterônimos. Ele se recria em múltiplas identidades.

Em entrevista concedida à Carmen Lúcia Tindó Secco, em Paris, no ano de 1999, e veiculada pela antologia Eroticus Moçambicanus (1999), o poeta discute as múltiplas identidades presentes em sua poesia e define o processo de produção de sua heteronímia:

No fundo a heteronímia reflecte o que mais tarde Lacan designou como
"descentramento do sujeito". Na errância, encontra-se a gênese da minha
heteronímia, como dizia Bruno Reis, em 1952. Ou como Pessoa escreveu: 'na
heteronímia reside a própria poesia'. De resto, a heteronímia é uma teia de fugas (...)
Fugas, descentramentos, que se traduzem por multiplicações de personalidades e
apetência de temas e formas, essência e subjectividade. Teia de fugas para escapar à
censura e, mais que isso, ultrapassar o provincianismo colonial, abrindo
Moçambique ao mundo, trazendo-lhe os ecos das vanguardas europeias, do
Movimento Pau-Brasil, da Negritude, entre outras correntes surgidas nas primeiras
décadas do século XX. (LEMOS, 1999, p. 143).

Rosicler Melo (2003) ressalta que entre o ortônimo Virgílio de Lemos e seus heterônimos existe um elo: a atração pelo mar, o azul e a forma voluptuosa do corpo, que pode ser a representação do corpo feminino ou da terra. Há também a presença de mitos antigos, além de alusões a grandes nomes da Literatura de todos os tempos. Angius defende que:

A influência de autores clássicos e modernos, como Camões e Pessoa, faz-se sentir; mas, ao ler a poesia que Virgílio de Lemos nos oferece, a memória do já lido apagase, transmuda-se em sensação de movimento e ondulação marítima. (ANGIUS, 1999, p. 136).

Duarte Galvão, um apaixonado pela língua portuguesa e por Lourenço Marques, é o heterônimo mais engajado socialmente, além de ser o mais rebelde. Essa é a face mais preocupada com as temáticas sociais, "com os preconceitos étnicos, com a miséria e com as injustiças”. (FONSECA, 2008, p. 45). Duarte Galvão assinou os poemas do livro Poemas do tempo presente, interditado e apreendido pela PIDE (Polícia Internacional de Defesa do 
Estado), em 1960, sob a acusação de ter "insuflado a bandeira nacional, órgão da soberania". O aspecto social, porém, não impede o desejo de expressão lírica dos sentimentos íntimos.

Lee-Li Yang, heterônimo no qual Virgílio de Lemos se desdobra em uma figura feminina, buscou assumir a condição de mulher independente para os moldes machistas da época. Uma mulher viajada e culta, que não se curvava ao domínio dos homens, ao contrário, enfrentava-os e buscava dialogar com eles. O poeta moçambicano ressalta aspectos de Lee-Li Yang:

Essa macaísta, no fundo, reivindicava o direito de ser dona exclusiva de seu corpo de mulher, numa sociedade machista, que marginalizava tanto as negras, como as brancas, as chinesas, indianas, as mulatas e as mestiças. (LEMOS, 1999, p. 146).

A sensualidade erótica é uma característica da lírica de Lee-Li Yang, uma vez que o erotismo do corpo se transfigurava em arma para liberação feminina; desdobrando-se em ritmo e visualidade. Curiosamente, os poemas de Lee-Li Yang eram dedicados ao seu amado Duarte Galvão.

Bruno Reis escreveu poucos poemas e manifestou-se, em maior parte, como cronista. Lemos justifica: "Vindo da poeticidade, é, entretanto, o heterónimo mais próximo de Ricardo Reis e também da crítica da história e da filosofia. Seus textos foram publicados, sobretudo, entre 1952 e 1953, no jornal Notícias da Tarde”. (LEMOS, 1999, p. 147).

Sobre o processo heteronímico em Virgílio de Lemos, Maria Nazareth Soares Fonseca, em Literaturas Africanas de Língua Portuguesa: percursos da memória e outros trânsitos (2008), afirma:

\begin{abstract}
A produção dos vários heterônimos dá mostra da luta empenhada, via literatura, contra o "império da razão'; demonstra o esforço para acompanhar inovações trazidas pelas vanguardas europeias e pelo modernismo brasileiro e romper com os paradigmas coloniais. A leitura assídua da obra de Fernando Pessoa e o fato de também ter vivido, como o poeta português, em Durban, na África do Sul, dão o mote para que o poeta, por diversas razões, assuma várias feições e diferentes identidades, como tentativa de levar a extremo as propostas das vanguardas, sobretudo o surrealismo, e o seu desejo de opor-se aos padrões racionais vigentes no contexto moçambicano de sua época. (FONSECA, 2008, p. 45).
\end{abstract}

Assim como ocorrera no Brasil do século XIX, especialmente com escritores como Machado de Assis e José de Alencar, nos países africanos colonizados por Portugal a imprensa e a literatura estiveram muito próximas. Impedidos de sobreviver exclusivamente da produção literária, os autores buscaram no jornalismo uma alternativa profissional, além de um meio de divulgação da literatura produzida nesses espaços. Fonseca (2007) traça um panorama das literaturas africanas e argumenta que o jornalismo tornou-se o meio de difusão 
de textos e manifestos, além de veículo de expressão e contestação, onde intelectuais e escritores protestavam severamente contra a máquina colonial. Mia Couto enfatiza: "Moçambique, nessa altura, vivia sob domínio português. Antecipados estávamos à nação. Lutar pela identidade desse país foi um sonho". (COUTO, 1999, p. 15).

Em Moçambique, historiadores e críticos literários consideram a publicação da revista Msaho (1952) como movimento significativo de ruptura com os códigos culturais estabelecidos. A revista se insere na trajetória de resistência já marcada pelos jornais $O$ Brado Africano e Itinerário. Nesta perspectiva, segundo Lemos, "Msaho pretendia uma visão aberta, liberta de preconceitos e militâncias estigmatizadas”. (LEMOS, 1999, p. 153). Reunindo tendências estéticas variadas, o primeiro número da revista trouxe poemas de Noémia de Souza, Alberto de Lacerda, Duarte Galvão, Ruy Guerra, Augusto dos Santos Abranches, Reinaldo Ferreira, Cordeiro de Brito e Domingos Azevedo. Intelectuais contrários à opressão e à discriminação dos negros. "Msaho começou com um número que foi ruptura, mas, ao mesmo tempo, 'um teste'. Queríamos saber como o governo de Moçambique e a censura, a PIDE, iriam reagir". (LEMOS, 1999, p. 152). Os versos abaixo transcritos, do poema Msaho dada, escrito na evocação de Msaho (movimento mais que revista, sempre poesia) e assinado pelo heterônimo Duarte Galvão, ilustram o impulso precursor da modernidade na poesia de Virgílio de Lemos:

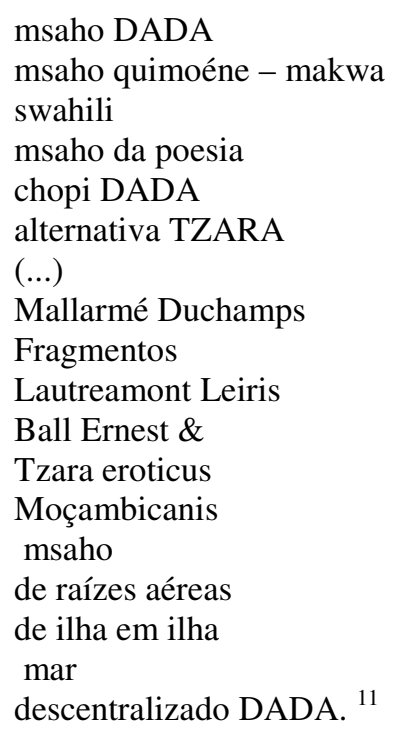

Inspirados na proposta cultural antropofágica à moda dos modernistas brasileiros, Virgílio de Lemos, Augusto Santos Abranches e Reinaldo Ferreira conceberam e fundaram o primeiro número de Msaho, que guarda, ainda hoje, seu modernismo. "A última revolução/ sou eu destino/ nómada que busca a ficcção/ de teus gritos corpo/ contra corpo/ no desgarre da

${ }^{11}$ GALVÃO, Duarte. Msaho dada, 1999, p. 30-31. 
ideia/ Liberdade". Os versos do poema $O$ tempo de Msaho ${ }^{12}$ reiteram a busca pela visão independente, liberta de preconceitos e militâncias estigmatizadas. Ao responder sobre as intenções e propostas dessa revista, Virgílio de Lemos destaca:

Msaho seria a grande ruptura, fundando, com avidez devoradora, uma antropofagia
cultpural, à maneira dos modernistas de São Paulo, Oswald de Andrade, Mário de
Andrade e também outros poetas das vanguardas europeias da América Latina, da
África, da Rússia, da Ásia, da China, do Japão, do mundo todo. Ora, Msaho seria,
como seu nome indica, movimento, ritmo, canto, dança, poesia, um hino à cultura
chopi do sul de Moçambique. Conhecíamos os marimbeiros de Zavala, seus cânticos
e sinfonias. Era preciso começar a valorizar os chopis, sempre criticados e
vilipendiados pelos shanganes, os quais também não poupavam os rongas.
Tínhamos que afastar o poder colonialista. Em suma, Msaho era um hino à
negritude. (LEMOS, 1999, p. 151).

Pensar sobre a escrita e veiculação de obras literárias em países que, como Moçambique, se constituíram no processo histórico da colonização europeia, implica também a reflexão sobre a figura do intelectual em trânsito, do poeta, do flâneur, tal como Virgílio de Lemos, visto que seus deslocamentos são tanto uma característica da sua formação cultural, quanto uma exigência da modernidade, que se constrói na constante movimentação entre espaços distintos. A condição de deslocamento torna-se, então, uma condição permanente para o intelectual moderno.

O escritor argentino Ricardo Piglia assegura que "hay cierta ventaja, a veces, en no estar en el centro. Mirar las cosas de un lugar levemente marginal (...) Este mirar al sesgo nos daria uma percepción, quizá, diferente, específica. (PIGLIA, apud PEREIRA, 2009, p. 72). Maria Luiza Scher Pereira (2009), à luz da explicação de Piglia, afirma que o intelectual periférico, aquele que está constantemente descentrando, mantém sua "mirada estrábica", o que lhe confere uma visão particularmente amplificada. Enquanto o intelectual metropolitano se reconhece apenas como o centro, o intelectual periférico é impelido a conhecer a margem e o centro, acostumando-se, assim, a transitar em ambos os lugares.

Virgílio de Lemos lançou mundo sua "mirada estrábica" e soube misturar em sua lírica experiências de cais e viagem. O maior desejo deste poeta, concretizado em suas poesias, era "abrir as portas da literatura moçambicana para que ela encontrasse sua independência, para que nascesse como uma literatura autônoma, deixando para trás a fase embrionária em que se encontrava" (LEMOS, 1999, p. 149). Para compor a poesia das ilhas, lavrou o desenho da palavra sobre o desejo; em um discurso enriquecido pela intertextualidade com vários poetas e culturas, marcado pelos trânsitos, permeado pelas

${ }^{12}$ GALVÃO, Duarte. O tempo de Msaho, 1999, p. 27-28.

Anu. Lit., Florianópolis, v.18, n. 2, p. 21-33, 2013. ISSNe 2175-7917 
vivências dos outros. A estética virgiliana, liberta e libertadora dos grilhões impostos pela colonização e outras formas de autoritarismo, recusou, também, recair no isolacionismo ou no provincianismo local.

\section{Referências}

ANGIUS, Fernanda. In: LEMOS, Virgílio de. Eroticus moçambicanus: breve antologia da poesia escrita em Moçambique (1944/1963) / Virgílio de Lemos \& heterônimos; Carmen Lúcia Tindó Secco (organização e apresentação). Rio de Janeiro: Nova Fronteira: Faculdade de Letras, UFRJ, 1999. p. 131-138.

BOSI, Alfredo. O ser e o tempo da poesia. São Paulo: Cultrix, Editora da Universidade de São Paulo, 1977

CHEVALIER, Jean. Dicionário de Símbolos: mitos, sonhos, costumes, gestos, formas figuras, cores, números. Tradução Vera da Costa e Silva. 24 ed. Rio de Janeiro: José Olympio, 2009. p. $107-110$.

COUTO, Mia. In: LEMOS, Virgílio de. Eroticus moçambicanus: breve antologia da poesia escrita em Moçambique (1944/1963) / Virgílio de Lemos \& heterônimos; Carmen Lúcia Tindó Secco (organização e apresentação). Rio de Janeiro: Nova Fronteira: Faculdade de Letras, UFRJ, 1999. p. 15-17.

FONSECA, Maria Nazareth Soares. Panorama das literaturas africanas de língua portuguesa. Cadernos CESPUC de Pesquisa: Belo Horizonte, n. 16. p. 13-69, set. 2007.

FONSECA, Maria Nazareth Soares. Literaturas africanas de lingua portuguesa: percursos da memória e outros trânsitos. Belo Horizonte: Veredas \& Cenários, 2008.

LEMOS, Virgílio de. Eroticus moçambicanus: breve antologia da poesia escrita em Moçambique (1944/1963) / Virgílio de Lemos \& heterônimos; Carmen Lúcia Tindó Secco (organização e apresentação). Rio de Janeiro: Nova Fronteira: Faculdade de Letras, UFRJ, 1999.

PEREIRA, Maria Luiza Scher. O intelectual em trânsito em um texto híbrido. In: SOUZA, Eneida Maria; MARQUES, Reinaldo (organizadores). Modernidades Alternativas na América Latina. Belo Horizonte: Editora UFMG, 2009.

MELO, Rosicler Ferraz de. O erotismo na poesia de Virgílio de Lemos (1944-1963): o eu que recorda. [Dissertação de Mestrado]. Faculdade de Letras da UFRJ, 2003.

SECCO, Carmen Lúcia Tindó Ribeiro. O imaginário das ilhas em alguns poetas moçambicanos. Revista Camoniana, v.18, 2006, p. 15-27.

SOUZA E SILVA, Manoel de. Do alheio ao próprio: a poesia em Moçambique. São Paulo: Editora da Universidade de São Paulo; Goiânia: Editora da UFG, 1996.

[Recebido em junho de 2013 e aceito para publicação em novembro de 2013] 


\section{Virgilio de Lemos: an itinerant intellectual}

Abstract: The aim of this essay is to investigate some salient features of the poetry of Virgílio de Lemos, who, by means of polyphony, revealed himself rebellious and transgressive when compared to the literary model that was the norm in Mozambique. The poet has created new images and vocabulary, printed new rhythm of his poetry, in order to reveal the multiple cultural knowledge present in their country. The production of various heteronyms (Duarte Galvão, Bruno Reis and Lee and Li Yang) reveals the effort to follow the innovations brought by the European avant-gardes, the Brazilian modernism, and break with the colonial paradigms . For the study presented here, we selected some texts published in the anthology Eroticus Moçambicanus (1999), organized by Carmen Lucia Tindo Secco (UFRJ). This book brings together the work cycles representative of Virgil, especially what was produced between 1944-1963. Virgil 's lyrical stand irreverence and transgression, constituting itself as a subversive attitude in search of identity, and the cry of a poet nonconformist repression against the colonialist.

Keywords : Identity. Poetry. Polyphony. Resistance. Virgilio de Lemos.

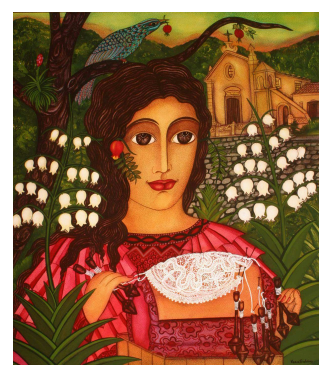

